\title{
РАЗДЕЛ ІІ.МЕНЕДЖМЕНТ
}

\author{
Бармута К.А. \\ Управление инновационным потенциалом малых и средних промышленных \\ предприятий в условиях модернизации экономики
}

Донской государственный технический университет (Россия, Ростов-на-Дону)

doi:10.18411/spc-08-04-2019-10

idsp: sciencepublic-08-04-2019-10

Малые и средние предприятия, в соответствии с принятыми для них критериями $\left[\begin{array}{ll}1, & 2\end{array}\right]$, играют стратегически важную роль в осуществлении модернизации национальной экономики и ее региональных подсистем, основным содержанием которой является замена ресурсоориентированной модели экономического развития на инновационную, основанную на знаниях, пространственной интеграции хозяйствующих агентов и цифровизацией основных секторов предпринимательской деятельности.

Несмотря на реализацию разнообразных форм и видов государственной поддержки субъектов малого и среднего бизнеса, уровень их развития все еще отстает от показателей развитых стран, в первую очередь по вкладу в ВВП (по различным оценкам величина расхождения составляет 15-25\%).

Нерациональной с точки зрения трендов современной экономики является отраслевая структура сектора малого и среднего бизнеса. Так, по данным Ростовстата, в структуре малых и средних предприятий, функционирующих в Ростовской области, ведущее место занимает оптовая и розничная торговля: по удельному весу малых предприятий $-30,6 \%$, по удельному весу рабочих мест $-21,7 \%$, по удельному весу оборота $-58,6 \%$. Затем следуют обрабатывающие производства и строительство. Доля других видов деятельности является небольшой и варьирует в пределах от $0,1 \%$ до 5\%.

Важность развития малого и среднего предпринимательства как одного из факторов модернизации российской экономики и общества в целом еще раз была подчеркнута Президентом страны на заседании Государственного совета по вопросам развития малого и среднего предпринимательства 7 апреля 2015 года. В.В. Путин заявил, что «развитие малого и среднего предпринимательства - не только одно из ключевых условий обновления страны, обновления экономики, повышения ее устойчивости, но и в целом нашего успешного развития вперед, реализации того огромного, творческого, предпринимательского потенциала, который, безусловно, есть у нашего народа» [3].

Сложившаяся ситуация в значительной мере связана с низкой эффективностью использования рыночного потенциала субъектов малого и среднего бизнеса, и прежде всего, его инновационной компоненты. Аналитическое исследование сектора малого и среднего бизнеса Ростовской области позволило выявить причины низкой инновационной активности (рисунок 1).

Особую актуальность в современных условиях необходимости ускоренного развития реального сектора экономики приобретает проблема активизации инновационного потенциала малых и средних промышленных предприятий. Это объясняется тем, что субъекты малого и среднего бизнеса, осуществляющие свою деятельность в промышленном секторе региона, пока еще выступают в качестве дополнений крупных предприятий и не играют заметной роли в активизации реального сектора экономики. Вместе с тем, венчурный капитал в индустриально-развитых странах мира сосредоточен именно на малых промышленных предприятиях, что с 
экономической точки зрения объясняется тем, что крупные промышленные предприятия стараются не рисковать и не привлекать те технологии, которые еще не проходили апробацию, которую и проводят малые промышленные предприятия [6, 7].

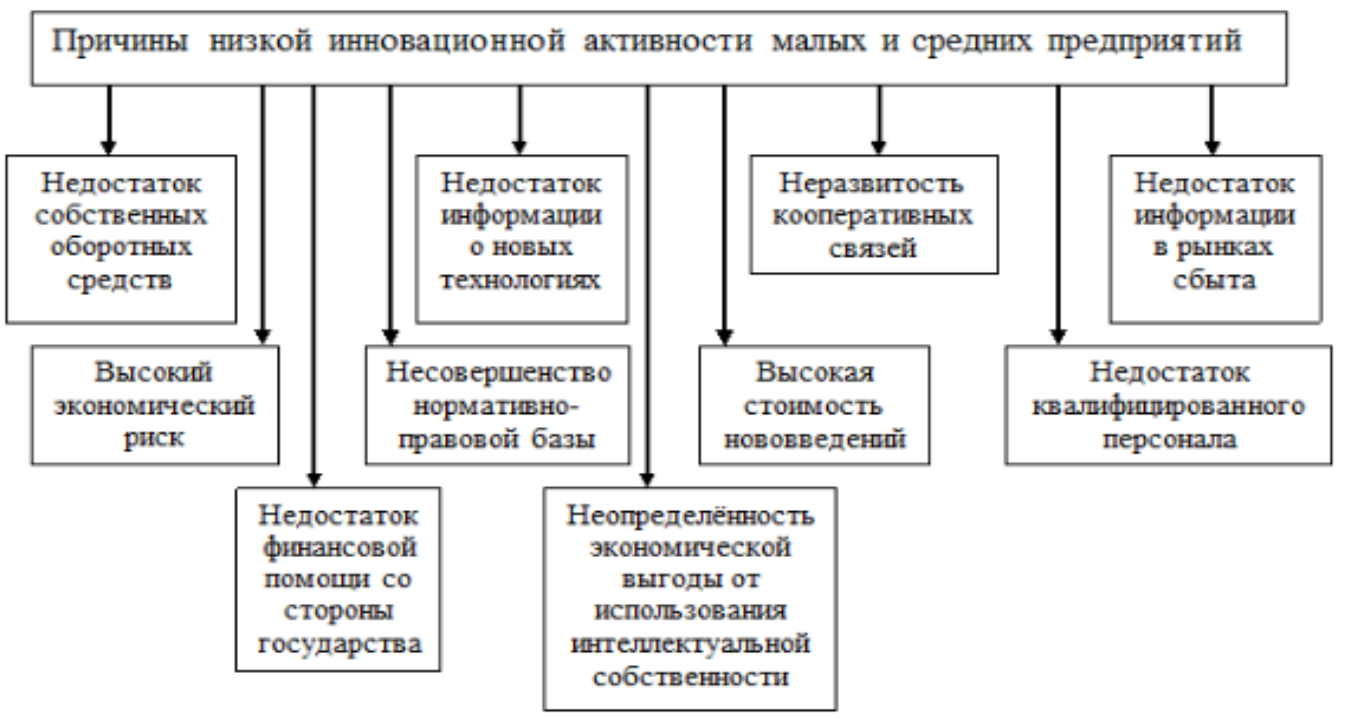

Рисунок 1 - Причины низкой инновационной активности мальх и средних предприятий (составлен автором с использованием источника [5])

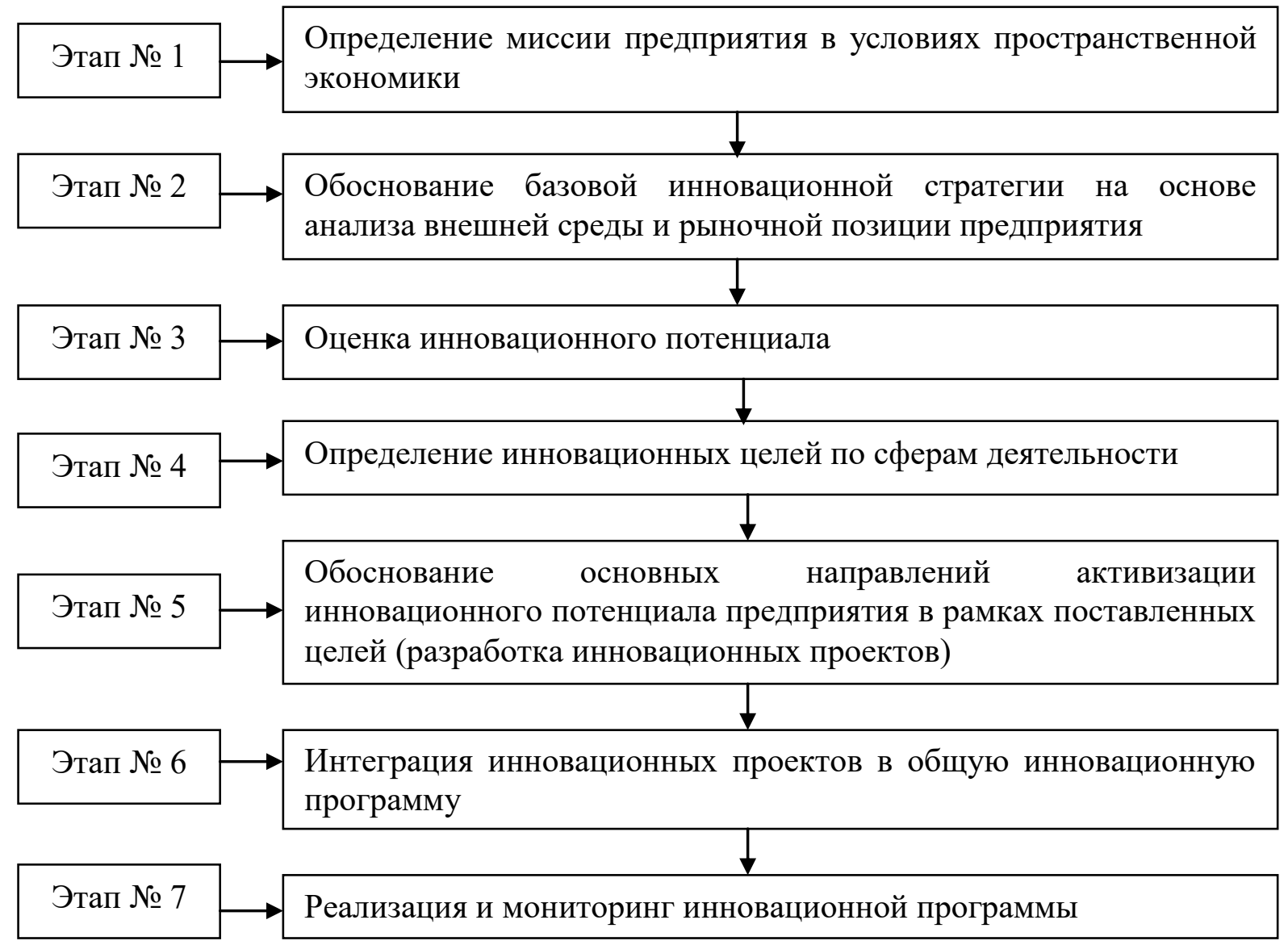

Рисунок 2 - Концептуальная модель управления инновационным потенцииалом мальх и средних промышленных предприятий (составлен автором)

Необходимость использования особого подхода к управлению инновационным потенциалом малых и средних промышленных предприятий объясняется, прежде всего, его сущностным содержанием, состоящим, по мнению большинства исследователей, в способности системы к трансформации фактического порядка вещей в новое состояние 
с целью удовлетворения существующих или новых потребностей предприятияноватора [4].

Изучение публикаций по проблеме управления инновационным потенциалом промышленных предприятий, изучение региональной практики функционирования сектора малого и среднего бизнеса, а также анализ позитивного зарубежного опыта позволяют сформировать следующую концептуальную модель в виде ряда взаимосвязанных этапов (рисунок 2).

Особый интерес, с точки зрения практической направленности, имеет этап, связанный с формированием основных направлений активизации инновационного потенциала малых и средних промышленных предприятий, учитывая специфику сектора малого и среднего предпринимательства в составе региональной социальноэкономической системы, особенности современных инновационных процессов и тренды их дальнейшего стратегического развития, в качестве основных направлений такой активизации, на наш взгляд, могут быть использованы следующие (рисунок 3).

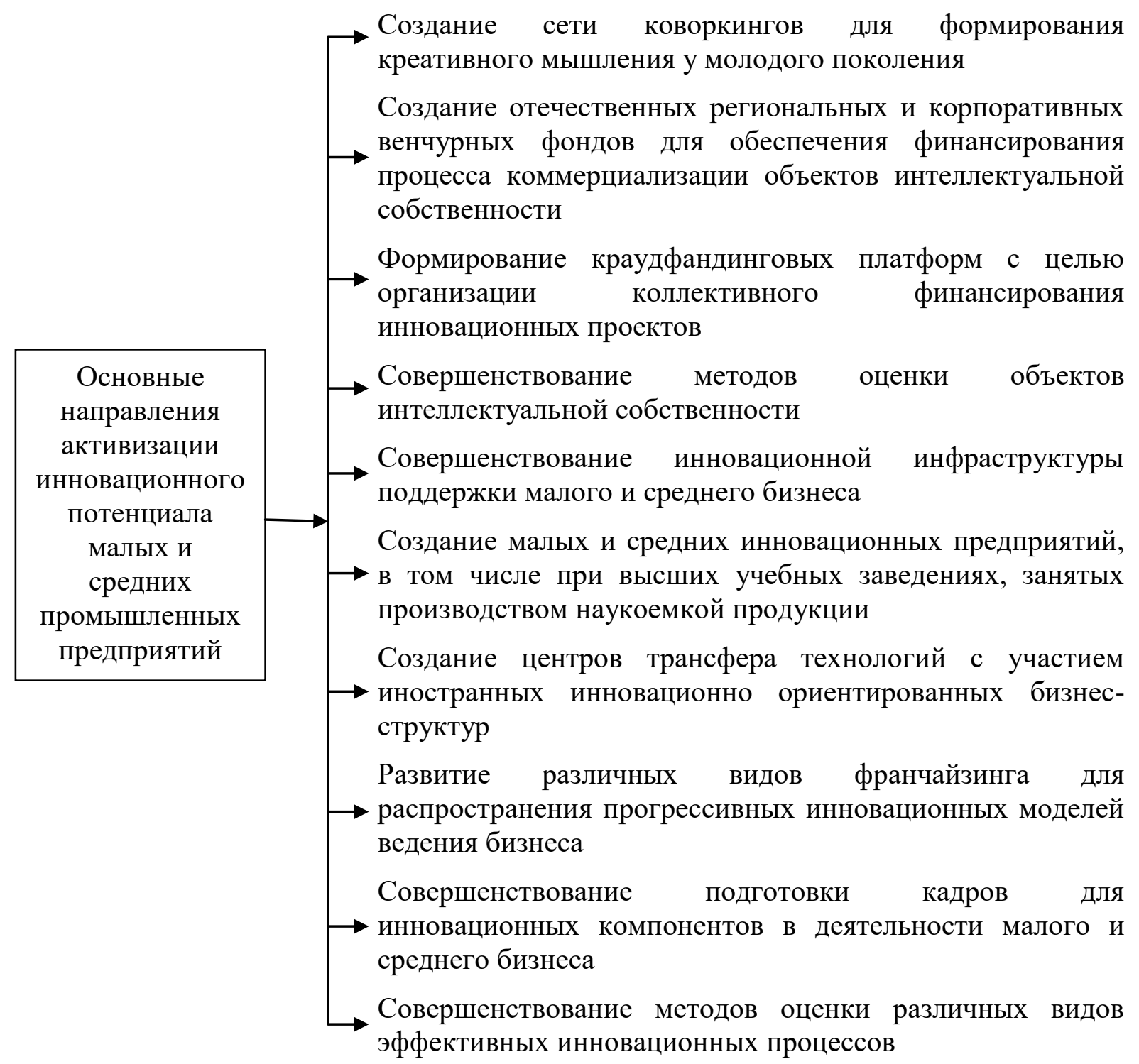

Рисунок 3 - Основные направления активизации инноваџионного потенциала малых и средних промылиенных предприятий (составлен автором)

Комплексное совершенствование инновационного потенциала малых и средних промышленных предприятий позволит, наряду с другими факторами осуществить модернизацию промышленного сектора региональной экономики и обеспечить его функционирования в параметрах экономики знаний с учетом ее пространственной и 
цифровой направленности в условиях развития международных интегрированных процессов, имеющих инновационный характер.

\section{$* * *$}

1. Федеральный закон от 24.07.2007 № 209-Ф3 (ред. от 27.11.2017) «О развитии малого и среднего предпринимательства в Российской Федерации» // СПС Консультант Плюс.

2. Постановление Правительства Российской Федерации от 22.06.2008 № 556 «О предельных значениях выручки от реализации товаров (работ, услуг) для каждой категории субъектов малого и среднего предпринимательства» // СПС Консультант Плюс.

3. Стенограмма заседания Государственного Совета по вопросам развития малого и среднего предпринимательства 7 апреля 2015 г. [Электронный ресурс] URL: http://kremlin.ru/news/48122 (дата обращения 16.01.2019)

4. Акулова Н.Г. Сущность и структура инновационного потенциала предприятия в системе антикризисного управления // МИР (Модернизация. Инновации. Развитие). - 2014. № 5(18) - С. 8690.

5. Лаврентьев В.А., Шарина А.В. Интеллектуальный потенциал предприятия: понятие, структура и направление его развития // Креативная экономика. - 2015. № 2.

6. Жигалов М.И. Малые промышленные предприятия как экономический феномен // Экономика и образование. - 2011. № 3 .

7. Пелевина К. Роль венчурного капитала в финансировании инноваций // Вестник института экономики РАН. - 2009. № 3. - С. 184-191. 